JALADRI (Vol. 6.1) (2020)

Jurnal Pendidikan Bahasa dan Sastra Daerah

http://jurnal.upmk.ac.id/index.php/jaladri/

\title{
NILAI-NILAI PENDIDIKAN KARAKTER DALAM NOVEL BUDAK MOTÉKAR KARYA JUNIARSO RIDWAN (TINJAUAN SOSIOLOGI SASTRA)
}

\author{
Annisa Ramadhani, Indah Purnamasari, M. Triesnaldi Aditia Sutrisno \\ anisa@gmail.com \\ Departemen Pendidikan Bahasa Sunda \\ Universitas Pendidikan Indonesia
}

\section{Info Artikel \\ Sejarah Artikel: \\ Diterima : 10 Januari 2020 \\ Disetujui : 10 April 2020 \\ Dipublikasikan : 25 April 2020}

Kata Kunci:

Pendidikan

karakter; novel

Budak Motékar;

sosiologi

\begin{abstract}
Abstrak
Penelitian ini berangkat dari pemikiran bahwa penanaman nilai-nilai pendidikan karakter dan pembentukan perilaku anak dapat dilakukan dengan berbagai media tanpa kecuali melalui novel Budak Motékar. Dengan demikian penelitian ini bertujuan untuk mengetahui nilainilai pendidikan karakter yang terkandung dalam novel Budak Motékar. Penelitian ini merupakan penelitian kualitatif dengan metode deskriptif, kemudian ditinjau dengan menggunakan sosiologi sastra. Sumber data dalam penelitian ini adalah novel Budak Motékar karya Juniarso Ridwan. Hasil analisis menunjukkan bahwa nilai-nilai pendidikan karakter yang terdapat dalam novel Budak Motékar meliputi jujur, tanggung jawab, bekerja keras, mandiri, kreatif, rasa ingin tahu, menghargai prestasi, peduli sosial, bersahabat, peduli lingkungan.
\end{abstract}


Key Words:

value of character education; novel Budak Motékar; sociology literature review.

The background of this research is thought of the values of character education and the formation of children's behavior can be done in various media including through Budak Motékar novel. This research is purposed to develop values of character education that contained in Juniarso Ridwan novel Budak Motékar. This research is qualitative with descriptive analysis method. This research is also using sociology literature approach. Data were collected by researcher where data was recorded and analyzed during periode of research to collect data from novel's text, then it processed and further analyzed in detailed. Results of this research are values of character education in Budak Motékar novel by Juniarso Ridwan which contain values of character educatior there are honest, responsibility, hard-driving, independently, creativity, reading interest, reward achievement, caring, communicative/friendly, and environmental care. 


\section{PENDAHULUAN}

Karya sastra merupakan satu sarana untuk mengungkapkan masalah manusia dan kemanusiaan. Sastra merupakan suatu kegiatan kreatif sebuah karya seni. Selain itu, sastra juga merupakan karya imajinatif yang dipandang lebih luas pengertiannya dari pada fiksi (Wellek dan Werren, 1993: 3-11).

Menurut Koswara (2010: 2) periode gelar sastra Sunda dibagi dua, yaitu satra lama dan modern. Jenis sastra lama di antaranya wawacan, guguritan, mantra, sisindiran, kakawihan dan cerita pantun, sedangkan jenis sastra modern yaitu novel, cerpen, sajak, dan drama. Dilihat dari bentuknya, sastra dibagi tiga, yaitu prosa, puisi, dan cerita drama.

Karya sastra muncul karena adanya keinginan dari pengarang untuk mengungkapkan ide-ide melalui imajinasinya. Meskipun bersifat imajinatif, kegiatan kreatif manusia yang dituangkan ke dalam bentuk karya sastra tentu tidak akan jauh dari pengalaman indrawinya, oleh karena itu bisa dikatakan bahwa karya sastra merupakan cerminan kehidupan nyata saat itu. Sehingga bisa dilihat dan dianalisis pola sosialisasi dan kebudayaan yang ada pada saat itu. Oleh sebab itu sangat masuk akal yang dikatakan Suherman (2019: 269) bahwa membaca karya sastra termasuk kedalam kegiatan literasi budaya. Selain itu, dalam kegiatan penciptaanya bisa dijadikan media dogma baik atau penanaman nilai-nilai bagi para pembacanya.

Nilai adalah sifat-sifat yang penting atau berguna bagi kemanusiaan (Poerwadarminto dalam Idhawati 2017: 11). Demikian juga penanaman nilai-nilai dalam karya sastra tulis novel, ialah dalam rangka memudahkan dalam sosialisasi di masyarakat. Kelanjutan dari nilai yang disajikan ialah untuk diyakini dan diingat sehingga akan muncul perasaan bersalah apabila melakukan sesuatu yang tidak selaras dengan nilai yang telah diyakini. Muara dari nilai-nilai ini ialah berupa wujud perbuatan yang menjadi karakter.

Zuriah (2008:26) menjelaskan bahwa pendidikan adalah usaha sadar dan terencana untuk mewujudkan suasana belajar dan proses pembelajaran agar peserta didik aktif mengembangkan potensi dirinya untuk memiliki kekuatan spiritual keagamaan, pengendalian diri, kepribadian, kecerdasan, akhlak mulia, serta keterampilan yang diperlukan dirinya, masyarakat, bangsa dan negara. Pendidikan nasional berfungsi untuk mengembangkan kemampuan membentuk watak serta peradaban bangsa yang bermartabat dalam rangka mencerdaskan kehidupan bangsa. Tujuan pendidikan itu adalah untuk mengembangkan potensi peserta didik agar menjadi manusia yang beriman dan bertaqwa kepada Tuhan Yang Maha Esa, berakhlak mulia, sehat, berilmu, cakap, kreatif, mandiri, dan menjadi warga negara yang demokratis serta bertanggung jawab. Karakter yang demikian disebutkan Suherman (2018: 112) dapat membentuk manusia yang seutuhnya, yaitu manusia yang seimbang lahir dan batinnya atau manusa manggapulia.

Menurut Samani dan Hariyanto dalam Febriana (2014: 93) karakter adalah cara berpikir dan berperilaku yang khas tiap individu untuk hidup dan bekerja sama, baik dalam lingkup keluarga, masyarakat, bangsa dan negara. Oleh karena itu, karakter seringkali dimaknai sebagai ciri personal. Sebagai contoh, karakter sombong, angkuh, dan sebagainya. Ini terjadi karena memang karakter merupakan penilaian tingkah laku satu individu terhadap individu lain.

Pendidikan karakter menurut Thomas Lickona (dalam Idhawati 2017: 13) adalah pendidikan untuk membentuk kepribadian seseorang melalui pendidikan budi pekerti, yang hasilnya terlihat dalam tindakan nyata seseorang, yaitu tingkah laku yang baik, jujur, bertanggung jawab, menghormati hak orang lain, kerja keras dan sebagainya.

Zubaedi (2011: 74), mengemukakan delapan belas nilai-nilai pendidikan karakter, yaitu 1) religius, 2) jujur, 3) toleransi, 4) disiplin, 5) kerja keras, 6) kreatif, 7) mandiri, 8) demokratis, 9) rasa ingin tahu, 10) semangat keras, 11) cinta tanah air, 12) menghargai prestasi, 13) bersahabat atau komunikatif, 14) cinta damai, 15) gemar membaca, 16) peduli lingkungan, 17) peduli sosial dan 18) tanggung jawab.

Nilai-nilai pendidikan karakter tersebut dikelompokkan menjadi lima, yaitu 1) nilai-nilai pendidikan karakter dalam hubungannya dengan Tuhan Yang Maha Esa, 2) nilai-nilai pendidikan karakter dalam hubungannya dengan diri sendiri, 3) nilai-nilai pendidikan karakter dalam hubungannya dengan sesama, 4) nilai-nilai pendidikan karakter dalam hubungannya dengan lingkungan, 5) nilai-nilai pendidikan karakter dalam hubungannya dengan kebangsaan.

Novel anak Budak Motékar karya Juniarso Ridwan, yang mengusung tokoh utama agar bisa bertahan hidup dalam keterbatasan, sangat erat 
kaitannya dengan pendidikan karakter sehingga novel ini dianggap berperan sebagai media pewarisan nilai-nilai terutama bagi anak-anak.

\section{METODE PENELITIAN}

Penelitian ini merupakan penelitian kualitatif dengan metode deskriptif analisis. Menurut Bodgan dan Taylor (dalam Basrowi, 2008: 20), metode penelitian kualitatif merupakan prosedur penelitian yang menghasilkan data deskriptif, berupa kata-kata tertulis atau lisan dari orangorang dan perilaku yang diamati. Dalam meneliti karya sastra menurut Ratna (dalam Febriana, dkk. 2014: 94), data-data formal penelitian kualitatif diambil dari teks novel dalam bentuk kata-kata, kalimat, dan wacana. Metode deskriptif analisis dilakukan dengan cara mendeskripsikan faktafakta, seterusnya dianalisis (Ratna, 2012: 53). Metode deskriptif digunakan dalam penelitian ini untuk mendeskripsikan dan menelusuri nilai pendidikan karakter dalam novel Budak Motékar karya Juniarso Ridwan.

Sumber data yang digunakan yaitu novel Budak Motékar karya Juniarso Ridwan. Novel ini merupakan cetakan pertama yang terbit pada tahun 2017, oleh penerbit Kiblat Buku Utama Bandung, dengan tebal 44 halaman. Dalam penelitian ini digunakan cetakan kedua tahun 2018.

Data dalam penelitian ini dikumpulkan dengan beberapa cara, yaitu teknik telaah pustaka dan teknik analisis secara langsung. Teknik telaah pustaka digunakan untuk mencari sumber-sumber teori kebutuhan referensi (nilai pendidikan karakter). Teknik analisis secara langsung digunakan untuk mengolah data nilai pendidikan karakter yang terdapat dalam novel Budak Motekar. Data penelitian ini adalah dialog dan paparan cerita yang mengandung nilai-nilai pendidikan karakter.

Instrumen utama dalam penelitian ini adalah peneliti sendiri. Peneliti mencatat dan menganalisis data selama penelitian untuk mengumpulkan data seperti kutipan yang diambil dalam teks novel. Kemudian peneliti sendiri mengolah dan menganalisis data secara rinci. Data dikumpulkan dengan cara sebagai berikut. Pertama, membaca dan memahami teks cerita novel secara berulang-ulang. Kedua, membaca buku-buku yang berhubungan dengan penelitian. Ketiga, mencatat setiap kata-kata atau kalimat yang mengandung nilai-nilai pendidikan karakter yang ditemukan sewaktu membaca teks novel.

\section{HASIL DAN PEMBAHASAN}

\section{A. Nilai Pendidikan Karakter}

Nilai-nilai pendidikan karakter yang terkandung dalam novel Budak Motekar karya Juniarso Ridwan banyak ditunjukkan dalam bentuk deskripsi cerita, dialog antar tokoh, dan juga respon para tokoh dalam menyikapi sesuatu. Novel pada umumnya terdiri dari paragraf dan kalimat yang merupakan hasil dari ide-ide serta karya imajinasi yang dituangkan oleh pengarang. Interpretasi yang timbul akan berbeda-beda karena berbedanya kemampuan pembaca. Pesan yang akan disampaikan pengarang dapat dipahami oleh pembaca dengan mudah. Untuk melihat pesan dibalik deskripsi cerita maka penulis menyampaikannya dalam bentuk potongan paragraf atau kalimat.

Adapun penjabaran nilai-nilai pendidikan karakter dalam novel Budak Motekar akan penulis jabarkan sebagai berikut.

\section{Nilai Pendidikan Karakter dalam Hubungannya dengan Diri Sendiri}

Hasil penelitian ini adalah nilai-nilai pendidikan karakter dalam hubungannya dengan diri sendiri berdasarkan teori pendidikan karakter yang dikemukakan oleh Yaumi.

\section{a. Jujur}

Jujur adalah perilaku seseorang yang didasarkan pada upaya menjadikan dirinya sebagai orang yang selalu dapat dipercaya dalam perkataan, tindakan, dan pekerjaan. Kutipan cerita yang menggambarkan nilai karakter jujur adalah:

Teu nepi ka burit, jam satengah tilu samangka téh geus payu kabéh.

"Ma, séép samangka téh. énjing mah badé ngabantun saratus siki," cék Nana ka indungna bari masrahkeun ladang duit samangka. (Ridwan, 2018: 40).

Berdasarkan kutipan di atas tergambar bahwa peristiwa tersebut terjadi pada waktu menjelang sore hari, di rumah Nana. Ketika itu Nana baru pulang dari berjualan semangka hasil panennya. Nana berkata kepada Emanya bahwa semangkanya telah habis terjual. Nana telah bersikap jujur kepada Emanya tentang hal yang terjadi pada dirinya, dan itu juga merupakan buah dari kejujurannya dalam berjualan.

Karakter jujur yang dimiliki oleh Nana adalah karakter jujur dalam perkataan, yakni sesuai hati nuraninya, tidak berbohong ataupun apa adanya. Apa yang diucapkannya dengan apa yang terjadi sama, dalam arti sesuai dengan kenyataan. 
Lauk emas mah, sabab lauk pelak, $k u$ barudak téh di kana gombangankeun. Keur nu boga balong. (Ridwan, 2018: 17).

Kutipan tersebut menggambarkan peristiwa yang terjadi di kolam milik Dodi. Ketika itu balong milik Nana memang sedang dikuras atau dibedahkeun. Terdapat berbagai jenis ikan yang hidup di kolam tersebut. Tetapi yang benar-benar dipelihara dan dikembangbiakkan oleh pemiliknya hanyalah ikan mas. Sikap anak-anak yang ikut menguras kolam tersebut menunjukkan sikap jujur dalam bertindak. Sebab anak-anak sudah tau bahwa ikan mas adalah kepunyaan pemilik kolam tersebut, maka anak-anak memisahkannya dengan hasil tangkapannya yang lain.

\section{b. Tanggung Jawab}

Orang yang bertanggung jawab memiliki karakter berbuat sebaik mungkin dan tidak menyalahkan orang lain ketika berbuat kesalahan karena manusia bertanggung jawab atas segala sesuatu yang dilakukannya. Kutipan cerita yang menggambarkan nilai karakter tanggung jawab adalah:

Nana teu némbal. Panonna neuteup ka lebah kebon nu kakara dipelakan sampeu, tuluy $k a$ lebah imah bilik. Imahna keur kosong. Indungna keur dagang. Nana

"Teu bisa milu, No. imah kosong." Walon

\section{"Kunaon?"}

"Imah kosong."

(Ridwan, 2018: 13)

Kutipan tersebut menggambarkan peristiwa yang terjadi ketika Tarno mengajak Nana untuk menemaninya pergi ke toko buku. Ketika itu Nana sedang mencangkul di kebun yang digarapnya. Karena Nana sedang mengerjakan sesuatu, maka ia menolak ajakan dari Tarno. Dari hal itu pun sudah tercermin bahwa Nana memiliki sikap tanggung jawab. Ditambah lagi, keadaan rumah Nana yang kala itu sedang kosong karena Emanya harus berjualan. Secara tidak langsung Nana juga sedang melaksanakan amanah yang lain, yaitu menjaga rumah. Maka dari itu Nana harus bertanggung jawab dengan menjaga rumah dan mengerjakan pekerjaannya yang lain, yaitu mencangkul.

Ngan hanjakal, éta kebon lain anuna. Anu uana. Sabada bapana maot, indungna kapapancénan tunggu kebon sakalian ngamangpaatkeunana. (Ridwan, 2018: 13).
Dari kutipan di atas dapat diketahui bahwa Nana menggarap kebun yang bukan miliknya. Sebelumnya kebun itu digarap oleh bapanya dan sepeninggal bapanya, emanya lah yang harus menjaga kebun itu. Karena emanya juga harus melakukan hal lain selain tunggu kebun, maka Nana lah yang bertanggung jawab untuk menggarapnya.

Unggal balik sakola Nana tara poho ngalongokan kebonna. Jukut nu ngaganggu dirabutan. Kebonna tara elat dibersihan. (Ridwan. 2018: 32).

Dari kutipan tersebut dapat diketahui bahwa Nana menggarap kebunnya dengan penuh tanggung jawab. Setiap pulang sekkolah ia selalu menengok kebunnya dan senantiasa merawat kebunnya sehingga kebunnya selalu bersih karena tidak pernah telat dibersihkan.

\section{c. Bekerja Keras}

Perilaku yang menunjukkan upaya sungguhsungguh dalam mengatasi berbagai hambatan belajar dan tugas, serta menyelesaikan tugan dengan sebaik-baiknya (Yaumi, 2014: 94). Kutipan cerita yang menggambarkan nilai karakter bekerja keras adalah:

Nana kacida tulaténna dina ngurus kebon. (Ridwan: 2018: 33).

Kata tulatén dalam kutipan kalimat di atas mewakili sikap Nana dalam bekerja keras.

\section{d. Mandiri}

Sikap dan perilaku yang tidak mudah bergantung kepada orang lain dalam menyelesaikan tugas (Yaumi, 2014: 98). Kutipan cerita yang menggambarkan nilai karakter mandiri adalah:

Nana geus bisa meuli tas kulit. (Ridwan: 2018: 43).

Pada bagian cerita sebelumnya, Nana mempunyai keinginan untuk membeli tas kulit. Tetapi kala itu ia tidak mempunyai uang untuk membelinya. Dari keinginannya, Nana mempunyai tekad untuk bertani dan menjual hasil ladang taninya. Sedikit demi sedikit ia mampu untuk mengumpulkan uang. Dalam perjalanannya menjadi pribadi yang mampu berkembang, ia pun menjadi seorang yang mandiri.

Nu leuwih matak ngagumbirakeun saréréa mah, Nana geus bisa nyumponan sagala kaperluanana $k u$ ladang késang sorangan. (Ridwan: 2018: 44). 
Kutipan kalimat teks di atas menggambarkan keadaan Nana yang dapat berkembang pesat sehingga bisa memenuhi kebutuhannya dengan hasil keringatnya sendiri. Keadaan Nana yang bisa mencapai titik tersebut adalah buah dari kerja kerasnya sehingga ia menjadi pribadi yang mandiri.

\section{e. Kreatif}

Kreatif bisa disebut sebagai kemampuan menciptakan dan mewujudkan gagasan baru untuk meningkatkan nilai tambah atau manfaat dari bahan-bahan yang sudah ada. Kutipan cerita yang menggambarkan nilai karakter kreatif adalah:

Pasosoré, Nana jongjon ngarautan awi. Nyieun langlayangan. (Ridwan: 2018: 20)

Kalimat yang dikutip menggambarkan keadaan Nana yang sedang membuat layangan. Layang-layang memang sangat mudah didapatkan di warung. Tetapi Nana lebih memilih untuk meraut dan membuatnya sendiri. Ini merupakan cerminan dari nilai kreatif. Bahkan bahan-bahan untuk membuat layangan tersebut dibuat oleh Nana sendiri dari kertas singkong.

Dodi jeung sobat-sobatna keur uplek ngobrol bari nyieun tali panggal. (Ridwan: 2018: 24).

Kalimat yang dikutip menggambarkan peristiwa yang terjadi di antara Dodi dan temantemannya. Mereka digambarkan sedang membuat panggal. Panggal adalah salahsatu dari sekian banyaknya kaulinan barudak. Dalam kutipan kalimat tersebut dapat dibuktikan nilai kreatif yang dimiliki Dodi dan teman-temannya. Mereka lebih memilih untuk membuat panggalnya masing-masing sebelum memainkannya.

Dikebonna lain baé aya pelak sampeu jeung samangka, ayeuna mah geus ditambaham ku pelak gedang. Maksudna, lamun keur teu usum samangka, Nana bisa ngajual gedang. (Ridwan, 2018: 44)

Kalimat yang dikutip menggambarkan peristiwa di kebun yang digarap oleh Nana. Awalnya Nana hanya menanam singkong di kebun yang digarapnya, kemudian berkembang menjadi menanam semangka pemberian pa Mantri, dan selanjutnya ditambah lagi dengan menanam pohon pepaya, dengan tujuan apabila semangkanya belum musim, ia bisa menjual pepayanya karena pepaya senantiasa berbuah. Itu semua merupakan pemikiran kreatif dari seorang petani muda, yaitu Nana. Pemikirannya yang kreatif menjadi faktor yang mendorong ia dalam perkembangannya.

\section{f. Rasa Ingin Tahu}

Rasa ingin tahu merupakan dorongan untuk tahu hal-hal baru, keingintahuan akan sesuatu menyebabkan seseorang akan mendekati, mengamati, ataupun mempelajari akan sesuatu benda atau suatu hal. Kutipan cerita yang menggambarkan nilai karakter rasa ingin tahu adalah:

"Kuring mah sok tara kaparengkeun nyieun langlayangan hadé. Teu gelenyé, sok beurat sabeulah."

"Kudu hadé atuh ngarautna."

Tarno nengetan Nana ngaraut. (Ridwan: 2018: 20).

Kutipan kalimat dari teks di atas menggambarkan peristiwa yang terjadi saat Nana meraut layangannya. Sementara Tarno digambarkan selalu gagal dalam membuat layangan, berbanding terbalik dengan Nana. Maka dari itu Tarno mengamati Nana yang sedang meraut supaya ia bisa mempelajarinya dan meningkatkan kemampuannya dalam meraut kerangka layangan. Sikap Tarno menggambarkan rasa ingin tahu.

"Cikan kuring ngilikan." dibuka.

Dodi mikeun bungkusan. Ku Nana tuluy ieu téh?"

"Geus garing gening. Kumaha cara melakna

"Urang tanyakeun baé ka Pa Mantri. Meungpeung aya kénéh di dieu, " cék Dodi.

"Apa, Nana badé naroskeun bab melak samangka ka Pa Mantri," Dodi nyarita ka bapana.

(Ridwan: 2018: 27).

Kutipan kalimat dari teks di atas menggambarkan rasa ingin tahu yang dimiliki Nana. Ketika itu, Nana mengamati benih semangka pemberian pa Mantri untuk bapanya Dodi. Nana juga mendapat bagian atas benih semangkanya. Tetapi baru kali itu Nana melihat benih semangka. Dari keadaan tersebut timbullah rasa ingin tahu Nana mengenai cara menanam semangka. Nana tidak menyia-nyiakan kesempatan. Kala itu juga ia menanyakannya pada pa Mantri, orang yang memberi benih tersebut.

"Kamari Pa Mantri Jarkasih datang ka imah. Maksudna rék ngajak masarakat patani jaradi anggota Koperasi Mitra Tani. Urang duaan ogé diajakan," cék Dodi. 
"Naon mangpaatna jadi anggota koperasi?" (Ridwan: 2018: 42).

Kutipan kalimat dari teks di atas menggambarkan peristiwa yang terjadi saat Dodi mengajak Nana untuk menjadi anggota koperasi. Sebelum mengajak Nana, sebenarnya Dodi sudah lebih dahulu ditawari menjadi anggota koperasi oleh pa Mantri. Kemudian Dodi mengajak Nana atas amanat dari pa Mantri dan atas sesama teman dan petani. Tetapi disitu Nana tidak langsung menerima tawaran dari Dodi. Nana merasa perlu memastikannya terlebih dahulu mengenai seluk beluk koperasi dan mengapa ia harus menjadi anggota koperasi. Keadaan tersebut menggambarkan rasa ingin tahu yang dimiliki oleh Nana.

\section{Nilai Pendidikan Karakter dalam Hubungannya dengan Sesama}

\section{a. Menghargai Prestasi}

Sikap dan tindakan yang mendorong dirinya untuk menghasilkan sesuatu yang berguna bagi masyarakat, serta mengakui dan menghormati keberhasilan orang lain (Yaumi, 2014: 105). Kutipan cerita yang menggambarkan nilai karakter menghargai prestasi adalah:

"Kayungyun budak téh. keun baé sina maju. Sugan baé jadi patani tuladan," kitu gerentes uana dina hiji mangsa. (Ridwan: 2018: 33).

Kutipan kalimat di atas menggambarkan sikap uwanya Nana yang bangga melihat Nana karena sudah mempunyai tekad untuk bertani di usianya. Uwanya mendukung apa yang dikerjakan Nana. Ia juga berharap supaya kedepannya Nana berkembang menjadi petani yang sukses.

Indungna reueus pisan ningali kamotékaran Nana. (Ridwan: 2018: 44).

Kutipan kalimat di atas menggambarkan rasa bangga seorang ibu terhadap anaknya. Indungnya Nana senantiasa mendukung Nana dalam segala hal. Termasuk ketika Nana memutuskan untuk mulai bertani di kebun uwanya. Dalam perjalananya, Nana semakin berkembang. Hal itulah yang membuat Indungnya merasa bangga.

\section{b. Peduli Sosial}

Sikap serta tindakan yang selalu ingin memberi bantuan kepada orang yang membutuhkan. Kutipan cerita yang menggambarkan nilai karakter peduli sosial adalah: mah."

"Téréh kaala hasilna geura melak samangka

"Enya, ngan dua satengah bulan, béjana."

"Ngan kadé baé poho ngagemukanana."

"Moal atuh, Nén. Gemukna gé rék maké gemuk kandang."

"Ti kuring baé gemukna mah. Asal daék ngakutna baé." (Ridwan: 2018: 30)

Kutipan kalimat dari teks di atas menggambarkan peristiwa yang terjadi ketika Nana sedang mengamati kebun semangkanya. Pada saat yang sama, datanglah Unen. Ia mengingatkan Nana supaya memberi pupuk dengan baik. Ia juga menawarkan pupuk kandang yang ada di belakang rumahnya. Kutipan tersebut menggambarkan sikap Unen yang peduli dengan temannya yang sedang membutuhkan.

Nana teu poho ka sobat-sobatna. Kabéh kabagéan ngasaan. Masing-masing dibéré dua. Barudak mani aratoheun. (Ridwan: 2018: 40-41).

Kutipan kalimat di atas menggambarkan peristiwa ketika Nana membagi hasil panen semangkanya kepada teman-temannya. Sikap Nana tersebut menggambarkan nilai peduli sosial. Bagaimanapun Nana memang bersahabat baik dengan Dodi, Tarno, dan Unen. Mereka juga senantiasa saling membantu dan saling berbagi.

\section{c. Bersahabat/Komunikatif}

Tindakan yang memperlihatkan rasa senang berbicara, bergaul, dan bekerja sama dengan orang lain (Yaumi, 2014: 106). Orang yang bersahabat akan membawa kedamaian dan kenyamanan bagi orang di sektarnya. Kutipan cerita yang menggambarkan nilai karakter bersahabat adalah:

Harita téh aya opat budak umur sawelas taunan. Ngabring leumpang sisi walungan. Rék ngaruseup. (Ridwan: 2018: 7).

Kutipan kalimat di atas merupakan bagian awal cerita ketika empat sahabat tersebut dalam perjalan untuk memancing. Latar tempat yang disebutkan adalah di pinggir sungai.

Nana bijil ti enggon. Teu ka pancuran, ngan koloyong baé ka tepas hareup. Ari jol ka hareup, sobat-sobatna Tarno, Dodi jeung Unén geus araya di buruan keur ngawangkong.

"Isuk kénéh geus saraged. Rék kamarana ieu téh?"

Barudak nu tilu pada nyorén korang jeung ngajingjing ayakan.

"Kapan Dodi rék ngabedahkeun balong téa. Nana rék milu?" (Ridwan: 2018: 16). 
Kutipan kalimat dari teks di atas menggambarkan peristiwa yang terjadi di depan rumah Nana. Ketika itu, Nana baru bangun tidur dan langsung menuju ke depan rumahnya. Ia tidak tahu bahwa teman-temannya sudah menunggunya. Hal tersebut menggambarkan nilai persahabatan. Teman-teman Nana dengan sabarnya menunggu Nana untuk berangkat bersama menuju kolam Dodi yang akan dibedahkeun.

"Lain, aya naon, asa bangun rarusuh?"

"Rék moro beurit!"

"Di mana?"

"Di sawah. Geus aya samingguna, sawah téh diranjah beurit. Paréna nepi ka lebur," walon Dodi.

"Rék milu?"

Tarno ngalieuk ka Nana. Tuluy duanana unggeuk.

Opatan tuluy arindit ka sawah. Rék moro beurit. (Ridwan: 2018: 21).

Kutipan kalimat dari teks di atas menggambarkan peristiwa ketika Dodi dan Unen dalam perjalanan ke sawah untuk membasmi tikus. Dalam perjalanannya mereka tidak lupa untuk mengajak kedua sahabatnya yaitu Nana dan Tarno.

Nana boga niat rék nyerek bangsat. Tapi kudu kumaha? Sorangan mah pamohalan. Manéhna téh budak, ari bangsat biheung teuing kolot.

Nana inget $k a$ sobat-sobatna. Enya, manéhna rék ménta tulung ka babaturanana. Manéhna yakin, tangtu babaturanana daék mantuan.

"Tangtu baé, kuring sabatur-batur baris mantuan," cék Tarno. (Ridwan: 2018: 34).

Kutipan kalimat dari teks di atas menggambarkan peristiwa ketika sudah tiga hari berturut-turut ada yang mencuri semangka Nana. Ketika itu Nana berniat untuk menangkap pencuri. Tetapi ia tidak mungkin melakukannya sendiri karena ia tidak tahu lawannya seperti apa. Kemudian ia meminta bantuan sahabatsahabatnya, dan tentu saja sahabat-sahabat Nana setuju untuk membantunya.

"Kamari Pa Mantri Jarkasih datang ka imah. Maksudna rék ngajak masarakat patani jaradi anggota Koperasi Mitra Tani. Urang duaan ogé diajakan," cék Dodi. (Ridwan: 2018: 42).
Kutipan kalimat dari teks di atas menggambarkan peristiwa ketika Dodi mengajak Nana untuk bergabung menjadi anggota koperasi. Sebelumnya, Dodi mendapat ajakan tersebut dari pa Mantri. Kemudian ia menyampaikan pesan pa Mantri kepada Nana. Dari hal tersebut dapat kita ketahui bahwa Dodi adalah sahabat yang paling dekat dengan Nana. Mereka berkembang bersama menjadi seorang petani yang teladan.

\section{Nilai Pendidikan Karakter dalam Hubungannya dengan Lingkungan \\ a. Peduli Lingkungan}

Sikap dan tindakan yang selalu berupaya mencegah kerusakan pada lingkungan alam sekitarnya, serta mengembangkan upaya-upaya untuk memperbaiki kerusakan alam yang sudah terjadi (Yaumi, 2014: 111).

Kutipan cerita yang menggambarkan nilai karakter peduli lingkungan.

Rék moro beurit. Geus aya samingguna, sawah téh diranjah beurit. Paréna nepi ka lebur," walon Dodi.

Kutipan kalimat dari teks di atas menggambarkan peristiwa ketika Dodi akan berangkat ke sawah untuk membasmi tikus yang sudah meranjah sawah ayahnya Dodi selama seminggu. Sikap Dodi tersebut menggambarkan nilai peduli lingkungan.

\section{B. Analisis Sosiologis}

Sosiologi sastra merupakan hubungan antara sastra dan masyarakat. Sastra seringkali lahir dari ungkapan perasaan masyarakat atau cerminan dari keadaan sosial yang terjadi dalam kelompok masyarakat. Aspek sosiologis yang dianalisis dalam penelitian ini adalah eksistensi karya itu sendiri, mencakup isi karya sastra, tujuan, dan halhal yang tersirat dalam karya sastra yang berkaitan dengan masalah sosial.

Berdasarkan analisis sosiologis dalam novel Budak Motékar, sangat terlihat bahwa penulis menggambarkan keadaan sosial di daerah pedesaan yang didominasi masyarakat santun dan selalu bergotong royong. Selain itu, setiap tokoh dalam novel ini digambarkan hidup sederhana, seperti halnya yang dilakukan orang-orang desa pada umumnya.

Karakter utama dalam novel ini digambarkan sebagai sosok yang senantiasa bekerja keras untuk mendapatkan apa yang dia inginkan. Dibantu orang-orang di sekitarnya, karakter utama tersebut akhirnya berhasil mendapatkan apa yang dia inginkan. 
Banyak hal positif yang terdapat dalam novel ini, di antaranya adalah perilaku jujur, giat dalam berusaha menggapai cita-cita, dan memanfaatkan kesempatan. Selain itu, tokoh antagonis dalam novel ini tidak terlalu menonjol, hanya digambarkan sebagai seseorang yang menghambat tokoh utama dalam medapatkan apa yang diinginkan. Hal inilah yang membuat novel Budak Motékar layak dijadikan referensi penerapan pendidikan karakter bagi anak usia sekolah dasar.

\section{KESIMPULAN}

Nilai pendidikan karakter yang terdapat dalam novel Budak Motékar karya Juniarso Ridwan meliputi: hubungannya dengan diri sendiri berjumlah 14 data dengan indikator jujur berjumlah 2 data, tanggung jawab berjumlah 3 data, bekerja keras berjumlah 1 data, mandiri berjumlah 2 data, kreatif berjumlah 3 data, rasa ingin tahu berjumlah 3 data. Nilai pendidikan karakter dalam hubungannya dengan sesama berjumlah 9 data dengan indikator menghargai prestasi berjumlah 2 data, peduli sosial berjumlah 2 data, bersahabat berjumlah 5 data. Nilai pendidikan karakter dalam hubungannya dengan lingkungan berjumlah 1 data dengan indikator peduli lingkungan.

Berdasarkan simpulan yang dikemukakan, maka implikasi penelitian pendidikan karakter dalam novel Budak Motékar adalah bahwa novel ini merupakan karya sastra yang sarat dengan muatan pendidikan karakter yang sangat bermanfaat dalam pembentukan karakter anak usia sekolah dasar.

\section{REFERENSI}

Basrowi dan Suwandi. 2008. Memahami Penelitian Kualitatif. Jakarta: Rineka Cipta

Departemen Pendidikan Nasional. 2008. Kamus Besar Bahasa Indonesia. Jakarta: Gramedia Pustaka Utama.

Febriana, dkk. 2014. Nilai-Nilai Pendidikan Karakter dalam Novel Rantau Satu Muara Karya Ahmad Fuadi: Tinjauan Sosiologi Sastra. Jurnal Bahasa, Sastra dan Pembelajaran. Vol 2 (No. 3). Diakses Online: http://ejournal.unp.ac.id

Idhawati, Diyah. 2017. Nilai-Nilai Pendidikan Karakter yang Terkandung dalam Novel Anak Rantau Karya Ahmad Fuadi.IAIN Salatiga. Skripsi. Jurusan Pendidikan
Agama Islam. Fakultas Tarbiyah dan Ilmu Keguruan. Diakses Online: repository.perpus.iainsalatiga.ac.id

Koswara, Dedi. 2010. Sastra Sunda Modern. Bandung: JPBD FPBS UPI.

Ratna, Nyoman Kutha. 2012. Penelitian Sastra: Teori, Metode, dan Teknik. Yogyakarta: Pustaka Pelajar.

Ridwan, J. 2018. Budak Motékar. Bandung: Kiblat Buku Utama.

Suherman, A. (2018). Jabar Masagi: Penguatan Karakter Bagi Generasi Milenial Berbasis Kearifan Lokal. Lokabasa, 9(2), 107.

Suherman, A., \& Nugraha, H. S. (2019, March). Culture and Citizenship Literacy in Sundanese Children's Literature. In Second Conference on Language, Literature, Education, and Culture (ICOLLITE 2018). Atlantis Press.

Suherman, A. (2019). Literacy Tradition of Sundanese Society-Indonesia. International Journal for Innovation Education and Research, 7(3), 262271. https://doi.org/10.31686/ijier.Vol7.Iss3. 1377

Wellek, Rene dan Austin Warren. 1993. Teori Kesusastraan (Diindonesiakan oleh Melani Budianta). Jakarta: Gramedia Pustaka Utama.

Yaumi, Muhammad. 2014. Pendidikan Karakter: Landasan, Pilar, dan Implementasi. Jakarta: Kencana Prenada media Group.

Zubaedi, 2011. Desain Pendidikan Karakter: Konsep dan Aplikasinya dalam Lembaga Pendidikan. Jakarta: Kencana Prenada Media Group.

Zuriah, Nurul. 2008. Pendidikan Moral dan Budi Pekerti dalam Perspektif Perubahan. Jakarta: Bumi Aksara 